\title{
Alcohol and Mortality from All Causes
}

\author{
SERGE RENAUD ${ }^{1}$, DOMINIQUE LANZMANN-PETITHORY ${ }^{1}$, RENÉ GUEGUEN ${ }^{2}$ and \\ PASCALE CONARD ${ }^{2}$
}

\author{
${ }^{1}$ Emile Roux Hospital, Public Assistance of Paris Hospitals France \\ ${ }^{2}$ Center of Preventive Medicine, Nancy, France
}

\begin{abstract}
A large number of prospective studies have observed an inverse relationship between a moderate intake of alcohol and coronary heart disease morbidity and mortality. Concerning death from all-causes, results are not unanimous. Alcohol intake was associated with a protection of all-cause mortality in England and USA physicians and the large study of the American Cancer Society. None of these studies separated the effects of different alcoholic beverages.

In our prospective studies in France on 35000 middle-aged men, we observed that only wine at moderate intake, was associated with a protective effect on all-cause mortality. The reason was that in addition to the known effect on cardiovascular diseases, a very moderate intake of wine, protected also from cancer and other causes as confirmed by Gronbaek in Denmark. Our recent results also indicate that the protective effect of a moderate intake of wine on all-cause mortality is observed at all levels of blood pressure and serum cholesterol.
\end{abstract}

Key words: Alcohol, mortality, wine.

Abbreviations: BMI: body mass index; CHD: coronary heart disease.

\section{INTRODUCTION}

A large number of studies have reported that a moderate intake of alcohol is associated with a lower risk of morbidity and mortality $(1,2)$ from coronary heart disease (CHD), more efficient on morbidity. These results however, do not imply that longevity is increased in alcohol drinkers. In Great Britain, Shaper et al. reported (3) in a prospective study on 7735 middle aged men, that in moderate drinkers there was a $34 \%$ lower mortality rate from CHD but no benefit in total cardiovascular and all-cause mortality. Another study concluded: "Our results are inconsistent with the belief that daily consumption of a few glasses of wine has salutary effects" (4). In that study, they did not evaluate wine drinkers but rather beer and spirit drinkers. Thus, they anticipated that the effect of wine could not be different from that of other alcoholic beverages.

\section{Alcohol and all-cause mortality}

Do we have further indications that moderate alcohol drinking does not lower death from all causes? In 1994, the same year of the Shaper study (3) Sir Richard Doll et al. (5), also in Great Britain, in their study on British physicians, reported that a moderate intake of alcohol (21 units/week) reduced by more than $20 \%$ mortality from all causes, in addition to the usual protective effect on CHD mortality. In USA, a prospective study on 22701 men, also physicians, reported that the consumption of 2 to 6 drinks of alcohol per week lowered mortality from all causes by 21 to $28 \%$ (6).

The question raised by these two studies involves the kind of alcoholic beverage drank by these physicians. Could it be that they normally drank more wine than the general population? However, in USA, in the largest study ever performed on the effect of alcohol (238 206 subjects)

Corresponding author: Serge Renaud, Emile Roux Hospital, Public Assistance of Paris Hospitals France. Service du Dr. Oliver Henry 1, avenue de Verdun - 94456 Limeil-Brévannes Cedex-France. Phone: 0683069248 Fax: 0145958392. Email: serge.renaud@erx.ap-hop-paris.fr 
(7) on mortality, but in motivated subjects, very moderate drinkers, a $20 \%$ reduction in the mortality from all causes was registered, for 1 to 3 drinks per day, a result similar to that observed in the British (5) and American physicians (6). Thus, at least three large prospective studies have observed a similar reduction in mortality from all causes for a moderate intake of alcohol. The question raised is why large studies have observed a similar protective effect of alcohol on all-cause mortality and not the previous smaller studies? Such a discrepancy could be due to the size of the cohort or/and possibly the type of alcoholic beverage consumed. Unfortunately, none of these prospective studies have evaluated the type of the alcoholic beverage consumed.

\section{Type of alcohol and all-cause mortality}

The first prospective study suggesting that the type of alcoholic beverage in addition to its quantity, could be important for the protective effect on mortality, was that of Gronbaek (8). In that study, for 3 to 5 drinks per day cardiovascular mortality was reduced by $47 \%$ in the wine drinkers, but the other causes were also $50 \%$ lower. An important issue was that the other causes were not reduced in the drinkers of beer and spirits.
Since French males are considered the largest consumers of wine in the world, we conducted a study in Eastern France that included 34014 middle-aged men (40 - 60 years at baseline) in which we evaluated mortality in relation to their alcohol intake, with a follow-up of $10-15$ years (9), In that study, every social class consumed wine, and the largest consumers were workers and tradesmen (48.9 and $47.6 \mathrm{~g} /$ day respectively). Higher classes such as high-level managers consumed only $36.2 \mathrm{~g} /$ day of wine. In that cohort, wine was the main alcohol consumed ( $82 \%$ of the total alcoholic beverages). A moderate intake of wine ( 2 - 3 glasses per day) was associated with a $24-31 \%$ reduction in all-cause mortality, in smokers, ex-smokers and nonsmokers.

In a subsequent study (10) with 36250 men, we evaluated separately the effect of wine, beer, and of wine + beer. Significant lower all-cause mortality was observed only with wine at a moderate intake (1 to 5 glasses/day). With beer, either representing more than $40 \%$ of alcohol or less, there was no reduction of the all-cause mortality, at any level of alcohol consumption. The reduction of all-cause mortality in moderate wine drinkers could be attributed to a lower death from cancer (by $20 \%$ ) and from other causes (by 28 to $42 \%$ ) shown in Figure 1.

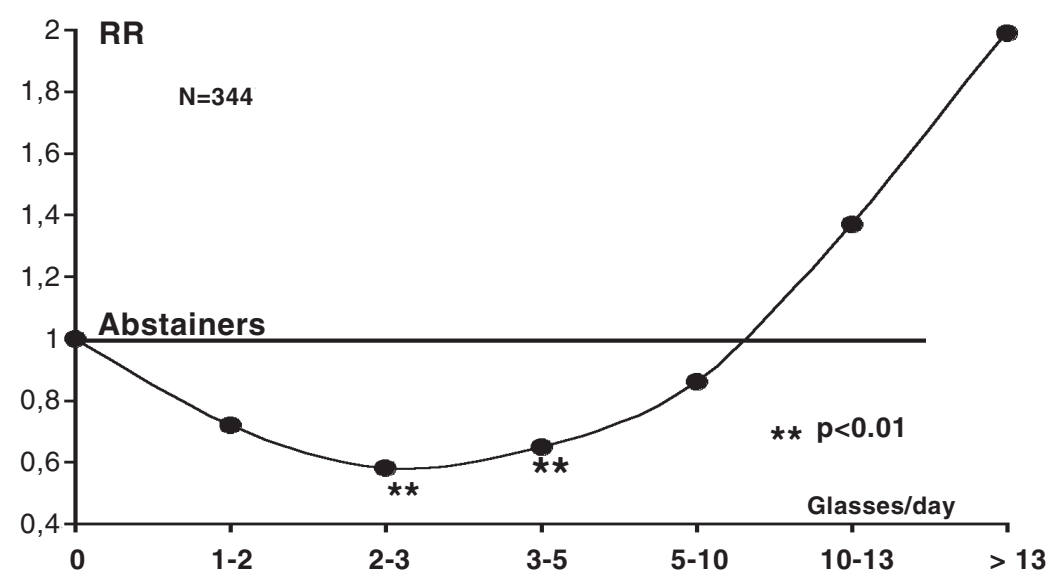

Figure 1. Death from other causes in wine drinkers of the Nancy cohort.

Relative risk of death from all-causes in relation to the intake of wine compared to abstainers, adjusted for age, smoking, BMI and education. Other causes were the sum of the causes of death with the exception of cancer, cardiovascular causes, cirrhosis and violent death. 
The specificity of wine for lowering the risk of all-cause mortality and cancer has been confirmed recently by Gronbaek et al. (11). It was only in wine drinkers that the all-cause mortality was lowered by more than $20 \%$ for an intake of up to 3 drinks per day. They also found that it was only wine but not spirits or beer that reduced cancer mortality by up to $20 \%$ (3 glasses of wine/day). As for cancer, the subsequent question was to evaluate on what types of cancer wine may have protective effects. Gronbaek et al. have already shown that wine drinking does not increase the risk of upper digestive tract cancer (12) as compared to beer or spirits.

In our cohort from Eastern France mentioned above, in 946 cases of cancer we evaluated the effect of wine drinking compared to abstainers (Fig. 2). The risk of both lung cancer and of other cancers was lowered by about the same extent for 1 - 3 glasses of wine (other cancers), and for 3 - 5 glasses (lung cancers). Above 5 glasses /day the risk of cancer was increased by $50 \%$.

Since it is only wine that offers some protection on the risk of cancer, that protection does not seem to be due to alcohol per se. Among the phenolic substances contained in wine, resveratrol is one substance that has been extensively studied in relation to cancer and other problems (13). It has been shown that resveratrol modulates lipoprotein metabolism, presents antioxidant and antiinflammatory activities, inhibits platelet aggregation and cellular events associated with cancer i.e. initiation, promotion and progression (13).

Wine and risk factors related to all-cause mortality

Risk factors such as serum cholesterol and smoking have been associated not only with cardiovascular but also with mortality from all causes. Since in France the risk factors seem to be as high as in other countries such as USA and Great Britain (14), we have evaluated, in the Nancy cohort, the effect that wine drinking would have on the risk of death. As shown in Figure 3, serum cholesterol in Eastern France does not appear to be associated with an increased risk of death from all-causes. Nevertheless, it is interesting to note that independent of the serum cholesterol level, the deaths from all-causes in wine drinkers is 22 to $32 \%$ lower than in non-drinkers or the other drinkers.

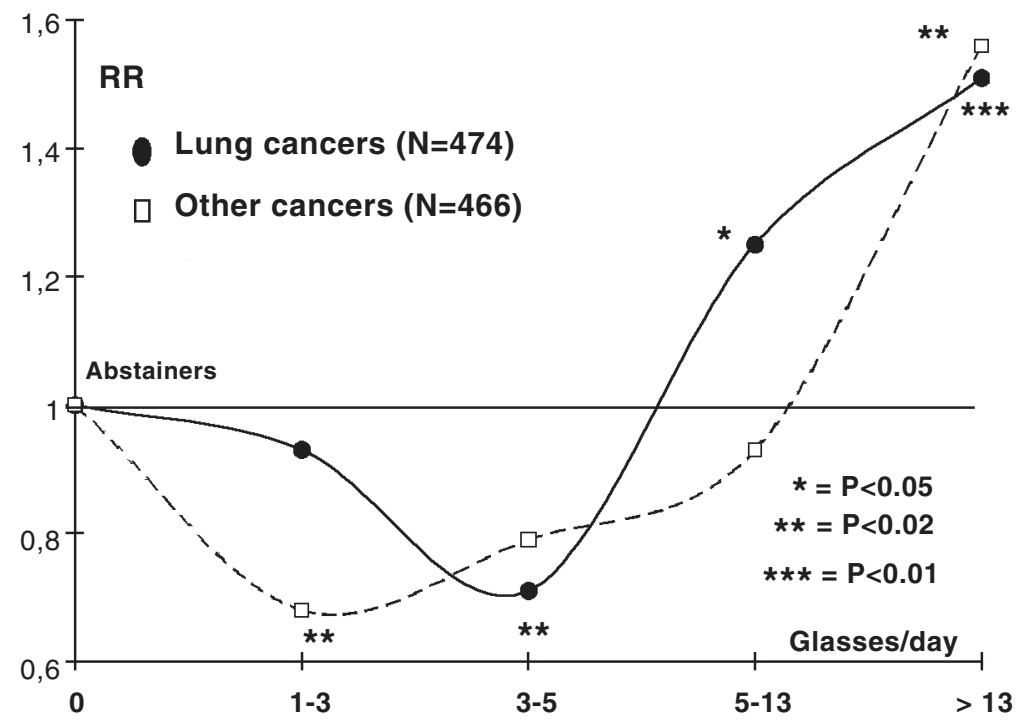

Figure 2. Death by cancer in wine drinkers of the Nancy cohort.

Relative risk of death in relation to the intake of wine compared to abstainers, adjusted as in Figure 1. 
Figure 4 shows the effects of alcoholic beverages on the risk of mortality from all causes in relation to smoking. Contrarily to what happens with cholesterol, in our cohort, smoking not only increases the risk of cardiovascular diseases but also increases the risk of death from all-causes by 4-fold in heavy smokers. The other drinkers present a similar risk than the non-drinkers while the wine drinkers present a lower risk of 18 to $29 \%$.

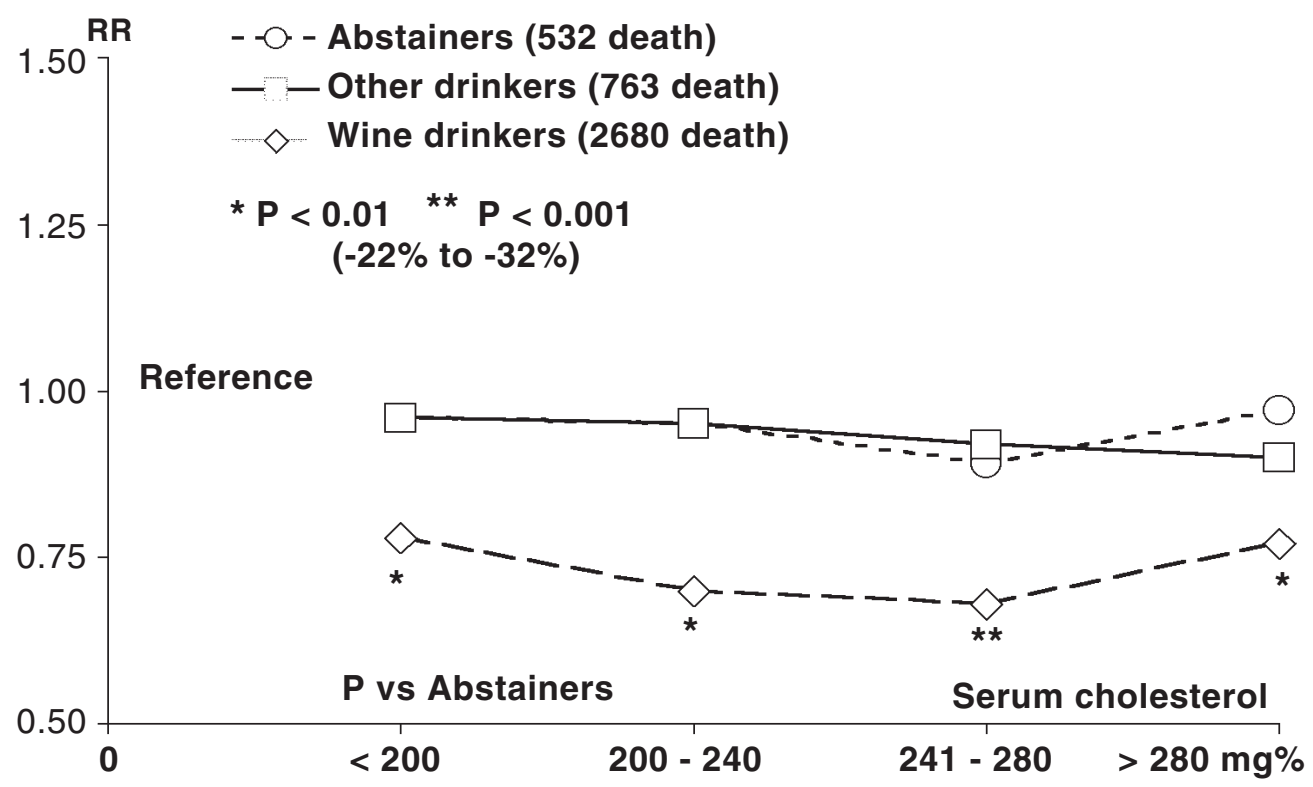

Figure 3. Death from all-causes in relation to serum cholesterol in the Nancy cohort.

Relative risk of death in relation to the intake of wine or of other alcohol beverages compared to abstainers, adjusted for age, smoking, education, physical activity, blood pressure and BMI.

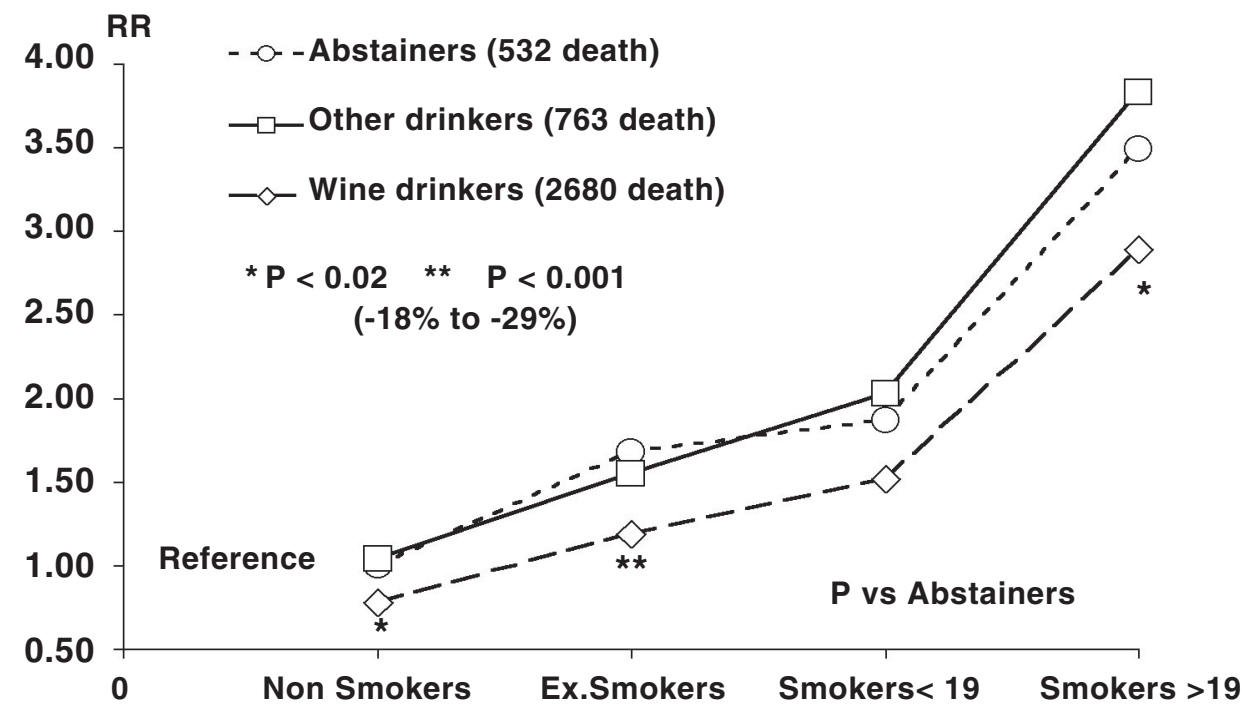

Figure 4. Death from all-causes in relation to smoking in the Nancy cohort.

Relative risk of death in relation to the intake of wine or of other alcohol beverages compared to abstainers, adjusted for age, cholesterol, education, physical activity, blood pressure and BMI. 


\section{CONCLUSION}

A high number of prospective studies have observed that a moderate intake of alcoholic beverages may protect from cardiovascular diseases, morbidity and mortality.

Recent studies on all-cause mortality suggest that only wine at very moderate intake, may be beneficial, through its effects on cancer and other causes $(15,16)$.

Even risk factors such as serum cholesterol and smoking do not seem to impede the protective effect of moderate wine drinking on all-cause mortality. Therefore, the protective effect of wine drinking on the effects of certain risk factors seems to be the direct explanation of the French Paradox, a low mortality rate despite a level of risk factors similar to that of countries such as USA and Great Britain.

\section{REFERENCES}

1. RIMM EB, GIOVANNUCCI EL, WILLETT WC, COLDITZ GA, ASCHERIO A, ROSNER B, STAMPFER MJ.(1991) Prospective study of alcohol consumption and risk of coronary disease in men. Lancet 338:464-468

2. KAGAN A, YANO K, RHOADS GG, McGEE DL (1981) Alcohol and cardiovascular disease: the Hawaiian experience. Circulation 64: III 27-31

3. SHAPER AG, WANNAMETHEE G, WALKER M (1994) Alcohol and coronary heart disease: a perspective from the British Regional Heart Study. Int J Epidemiol 23:482-494

4. LEINO EV, ROMELSJO A, SHOEMAKER C, AGER CR, ALLEBECK P, FERRER HP, FILLMORE KM, GOLDING JM, GRAVES KL, KNIEP S. (1998) Alcohol consumption and mortality. II. Studies of male populations. Addiction 93:205-218

5. DOLL R, PETO R, HALL E, WHEATLEY K, GRAY $R$ (1994) Mortality in relation to consumption of alcohol: 13 years' observations on male British doctors. BMJ 309:911-918

6. CAMARGO CA JR, HENNEKENS CH, GAZIANO JM, GLYNN RJ, MANSON JE, STAMPFER MJ (1997) Prospective study of moderate alcohol consumption and mortality in US male physicians. Arch Intern Med 157:79-85

7. THUN MJ, PETO R, LÓPEZ AD, MONACO JH, HENLEY SJ, HEATH CW JR, DOLL R. (1997) Alcohol consumption and mortality among middleaged and elderly U.S. adults. N Engl J Med 337:17051714

8. GRØNBÆK M, DEIS A, SØRENSEN TI, BECKER U, SCHNOHR P, JENSEN G (1995) Mortality associated with moderate intakes of wine, beer, or spirits. BMJ 310:1165-1169

9. RENAUD SC, GUEGUEN R, SCHENKER J, d'HOUTAUD A (1998) Alcohol and mortality in middle-aged men from eastern France. Epidemiology 9: $184-188$

10. RENAUD SC, GUEGUEN R, SIEST G, SALAMON R (1999) Wine, beer, and mortality in middle-aged men from eastern France. Arch Intern Med 159:1865-1870

11. GR ØNBÆK M, BECKER U, JOHANSEN D, GOTTSCHAU A, SCHNOHR P, HEIN HO, JENSEN G, SØRENSEN TI. (2000) Type of alcohol consumed and mortality from all causes, coronary heart disease, and cancer. Ann Intern Med 133:411-419

12. GRØNBÆK M, BECKER U, JOHANSEN D, TONNESEN H, JENSEN G, SØRENSEN TI (1998) Population based cohort study of the association between alcohol intake and cancer of the upper digestive tract. BMJ 317:844-847

13. JANG M, CAI L, UDEANI GO, SLOWING KV, THOMAS CF, BEECHER CW, FONG HH, FARNSWORTH NR, KINGHORN AD, MEHTA RG, MOON RC, PEZZUTO JM. (1997) Cancer chemopreventive activity of resveratrol, a natural product derived from grapes. Science 275:218-220

14. KUULASMAA K, TUNSTALL-PEDOE H, DOBSON A, FORTMANN S, SANS S, TOLONEN H, EVANS A, FERRARIO M, TUOMILEHTO J. (2000) Estimation of contribution of changes in classic risk factors to trends in coronary-event rates across the WHO MONICA Project populations. Lancet 355:675-687

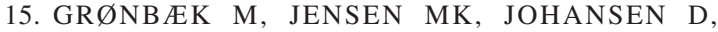
SØRENSEN TIA, BECKER U (2004) Intake of Beer, Wine and Spirits and Risk of Heavy Drinking and Alcoholic Cirrhosis. Biol Res 37: 195-200

16. LETENNEUR L (2004) Risk of Dementia and Alcohol and Wine Consumption: a Review of Recent Results. Biol Res 37: 189-193 